\title{
Chapter 5 \\ Health Trajectories in People with Cystic Fibrosis in the UK: Exploring the Effect of Social Deprivation
}

\author{
David Taylor-Robinson, Peter Diggle, Rosalind Smyth, \\ and Margaret Whitehead
}

\section{Cystic Fibrosis As a Case for Studying Health Inequalities}

Exploring the reasons for inequalities in outcomes in people with cystic fibrosis (CF) offers a unique opportunity to develop our understanding around pathways in inequalities in health more generally. Because CF is genetically determined, a socio-economic difference in incidence is not expected, but there may be important differences in outcomes over the course of people's lives.

Studies across the world have consistently shown that people from socioeconomically disadvantaged backgrounds experience worse health than those in more socio-economically advantaged positions. These inequalities in health outcomes are preventable, amenable to policy intervention, and they are unjust. In the UK and internationally, policies are being implemented to try to reduce health inequalities, with limited success, since for many important health outcomes, such as life expectancy in the UK, despite continuing overall improvements, significant inequalities remain (Marmot et al. 2010; Barr et al. 2012). In order to develop more effective interventions, we need a better understanding of how, and when, these health differences are generated and maintained.

This chapter brings together findings from our previously published longitudinal registry studies examining the effect of social deprivation on longitudinal clinical outcomes, healthcare use and employment opportunities in people with cystic

D. Taylor-Robinson $(\bowtie) \cdot$ P. Diggle $\bullet$ M. Whitehead

University of Liverpool, Liverpool, UK

e-mail: David.Taylor-Robinson@liverpool.ac.uk; P.Diggle@liverpool.ac.uk;

Mmw@liverpool.ac.uk

R. Smyth

UCL, London, UK

e-mail: rosalind.smyth@ucl.ac.uk 
fibrosis (CF), and draws on material from the lead author's PhD thesis, from which some sections are reproduced (Taylor-Robinson 2013; Taylor-Robinson et al. 2013a, b). Studying the health of people with CF in this way provides a valuable case study to investigate the impact of social deprivation on health and social outcomes, in a chronic condition without a socio-economic gradient in incidence. Despite this 'level playing field' at the outset, the processes by which differential outcomes in $\mathrm{CF}$ are generated are unclear. Elucidating these mechanisms is important to inform policies, both to improve care in $\mathrm{CF}$, and to reduce inequalities in health more broadly.

\section{Key Features of Cystic Fibrosis}

$\mathrm{CF}$ is an inherited, chronic, progressive condition occurring in around 1 in 2500 live births in the UK, and affecting over 9000 individuals, with around 300 new diagnoses annually (Dodge et al. 2007; CF Trust 2013). CF is the commonest serious inherited disease among white populations, and is caused by mutations in the $\mathrm{CF}$ transmembrane conductance regulator (CFTR) gene, resulting in thick secretions that impair various organs, particularly the respiratory and digestive systems. It is an autosomal recessive condition; inheritance requires receiving two copies of the defective CFTR gene, one from each parent (Davies et al. 2007). Most children are diagnosed in the first few months of life, and subsequently require intensive support from family and health care services. Most patients die prematurely from their disease through respiratory failure, but with increasing survival into adulthood, $\mathrm{CF}$ is best understood as a complex, multisystem disease.

Survival beyond the first few years of life was rare in the 1940s, but UK children born in the twenty-first century are now estimated to have a median survival of over 50 years of age (Dodge et al. 2007). Survival in CF has increased under the influence of improved treatment and management, improved nutrition and better living conditions (Davies et al. 2007; Schechter 2004), but these improvements do not appear to have been shared equally, since studies in both the US and UK have demonstrated differences in survival by socio-economic status (SES) (Schechter et al. 2001; O'Connor et al. 2003; Britton 1989). The social patterning of survival in CF suggests that social factors - the 'social determinants of health' - are having an important effect on outcomes. Utilising some of the unique characteristics of CF to explore the causes of these differences can offer broader insights.

$\mathrm{CF}$ is thus an interesting case conceptually for the study of pathways to inequalities in health: as a disease of autosomal recessive inheritance where carriers are unaffected, there is no social bias in incidence (Fig. 5.1), but there is potential for a social gradient in health care use, disease outcome, and social consequences to develop. CF thus opens up opportunities for inequalities research, because it offers both homogeneity, in terms of the population affected by the disease at the outset, and yet great variation in outcomes that can be explored. These two characteristics make for a promising "tracer condition" to improve our understanding of pathways to differential outcomes. 


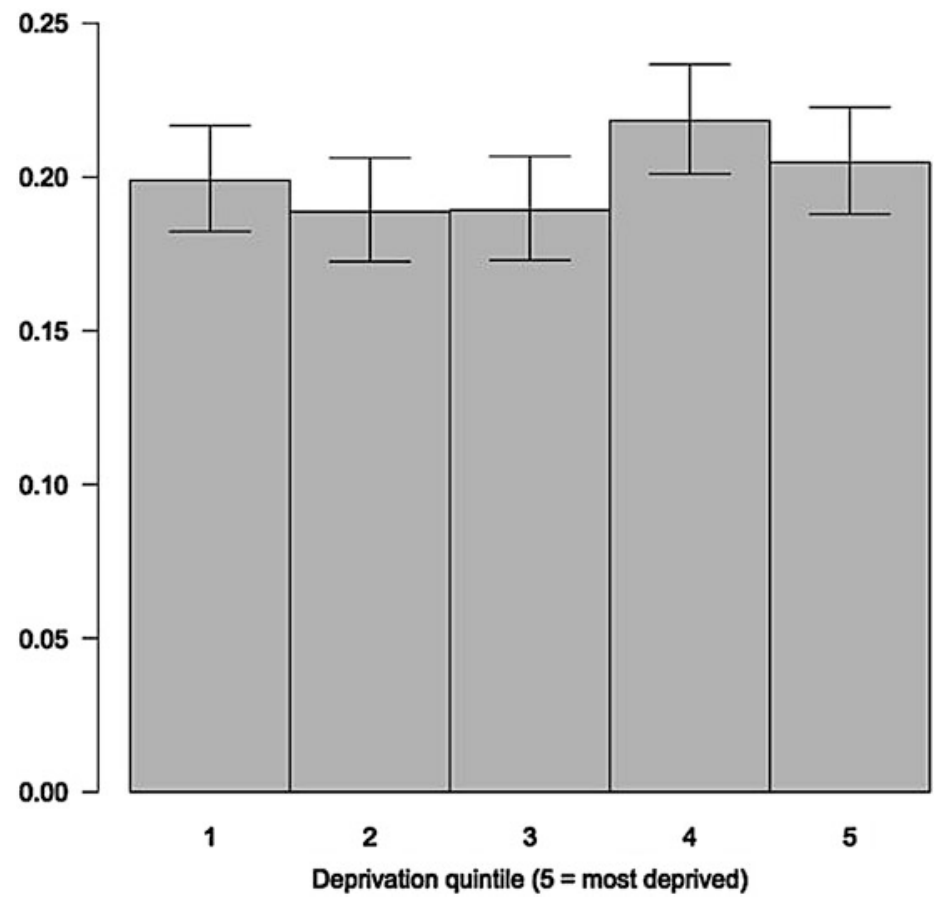

Fig. 5.1 Distribution of incident cases of CF in the UK by deprivation quintile 1996-2010. Error bars represent $95 \%$ binomial CIs $(n=2066)$ (Source: Adapted from Taylor-Robinson et al. 2013b)

\section{Clinical Management of CF}

Describing the management of CF in any depth is beyond the scope of this chapter, but for a succinct review see Davies and colleagues (2007). In brief, the key treatment outcomes considered in the analysis relate to respiratory and nutritional therapies:

- Treatment of respiratory infections with antibiotics is a central pillar of CF therapy including for prophylaxis; eradication of infections; long-term treatment of chronic infection, and treatment of acute exacerbations. The aim is to prevent initial bacterial infection in children, and promptly treat acute infections using antibiotics. Acute chest infections (exacerbations) are treated with oral, nebulised, and/or IV antibiotics.

- DNase is an inhaled mucolytic that breaks down the thick sputum in the lungs. This was first commercially available in 1992, and was the first treatment to demonstrate an improvement in lung function in CF (Fuchs et al. 1994).

- The main aims of nutritional support in CF are to achieve optimal nutritional status, and allow normal growth and development throughout childhood. Pancreatic enzyme insufficiency leads to malabsorption of fats, diarrhoea, and failure 
to thrive, and this is compounded by lung disease and infection, which further increases calorie requirements. Thus recommendations are for early nutritional support with adequate pancreatic replacement management, as this has been shown to improve growth and subsequent lung function (Konstan et al. 2003; Munck et al. 2009).

\section{Previous Research on Health Inequalities and CF}

People with CF from more disadvantaged groups in the UK and US die earlier than those from more advantaged backgrounds. In the UK, the first study to look at social differences in survival in CF found a consistent trend from 1959 to 1986 towards higher age at death in CF patients in more advantaged social groups on the basis of occupational class (Britton 1989). The authors speculated that the observed lower survival chances in lower social classes could relate to lack of access to the appropriate services, poorer nutrition, increased parental smoking, and poorer quality housing.

Evidence from the US corroborated these findings, and indicated higher survival rates in the 1980s and 1990s among more advantaged socio-economic groups, measured by Medicaid status and area-based income, compared with their less advantaged counterparts (Schechter et al. 2001; Schechter 2004; O'Connor et al. 2003). For instance the adjusted risk of death was around four times higher in CF patients with Medicaid cover (used as a surrogate for poverty) compared to those without Medicaid cover (Schechter et al. 2001). Two studies from the US showed differences in lung function on the basis of measures of SES. For instance Schechter et al. also showed significantly lower percent predicted forced expiratory volume in one second $\left(\% \mathrm{FEV}_{1}\right)$ at age 5 in the Medicaid patients $(9.2$ percentage points, $95 \%$ CI 7.1-11.4), and this gap increased slightly in an age dependent manner up to age 20. O'Connor et al. extended the work of Schechter's team by demonstrating a social gradient in the relationship between area-based income in the US, and mortality rates, lung function and weight (O'Connor et al. 2003). The authors point out the limitations of the ecological (area-based) measure of SES used in their analysis, and suggest that the associations observed may be due to poor adherence to medications, or local environmental conditions.

In many chronic illnesses, differences in access to specialist health care by SES are evident. These differences often contribute to the exacerbation of health inequalities, since a bias towards more advantaged groups is widespread across health care (Stirbu et al. 2011). This could be particularly important in the context of inequalities in outcomes for a disease like $\mathrm{CF}$, where treatment advances have had such a profound effect on survival. The studies exploring access to services and treatments in CF have been predominantly from the US, and have demonstrated a mixed picture, depending on the type of treatment under consideration, and the exact measure of SES used (O'Connor et al. 2003; Schechter et al. 2009, 2011). For instance, one study showed greater access to intravenous (IV) antibiotics for older 
children, on the basis of area-based income, but also showed no difference in access to DNase, another important treatment in CF, using Medicaid status as a measure of SES (Schechter et al. 2009). Overall the US studies have played down the role of health service factors in the generation of health disparities in CF. However, it is debatable how much of this evidence can be generalized to other health care settings, especially to the UK context, where access to health services is free at the point of use.

\section{Using the Diderichsen Model to Study Inequalities in CF Outcomes in the UK}

To gain a better understanding of when and how inequalities in outcomes develop in cystic fibrosis in a UK context, the studies summarised in the subsequent sections of this chapter explored the effect of deprivation on growth, nutrition, lung function, risk of Pseudomonas aeruginosa colonisation, and the use of major cystic fibrosis treatment modalities in a UK-wide population cohort, in the context of a the British NHS, a universal healthcare system, free at the point of use (Taylor-Robinson 2013; Taylor-Robinson et al. 2013a, b).

The studies involved longitudinal analyses of individual level patient data from the UK CF Registry, which is supported and co-ordinated by the UK CF Trust (2013; Adler et al. 2008), and records information about the health and treatment of patients with CF from diagnosis onwards. The Registry is estimated to include nearly all people with CF in the UK population (Mehta et al. 2004) and is therefore ideally suited to the study of outcomes and treatments across the whole socioeconomic spectrum in the UK society. The studies use postcodes to link individuals to small area deprivation measures in the UK as a measure of socio-economic status (SES), since individual level measures of patient SES, such as parental education level, were not available. The indices of multiple deprivation combine economic, social and housing indicators measured at the census into a fine grained composite deprivation score for small areas in the UK constituent countries (ONS 2011).

The analyses were informed by the Diderichsen model of pathways to health inequalities (Diderichsen et al. 2001). This model captures key concepts in our contemporary understanding of how health inequalities are generated, and was used as the conceptual basis for the work of the WHO Commission for Social Determinants of Health (CSDH 2008). The framework conceptualises the generation of health inequalities occurring through four main pathways over the life course (Fig. 5.2): through social stratification itself, which is the process by which people are sorted into different social positions (for example by social inequalities in the education system); because social stratification leads to differential exposure to risk factors (for example children living in poverty are more likely to be exposed to secondhand smoke in the home); differential vulnerability at the same level of exposure (for example due to clustering of cardiovascular risk factors, smoking is more harmful 
Society

Individual

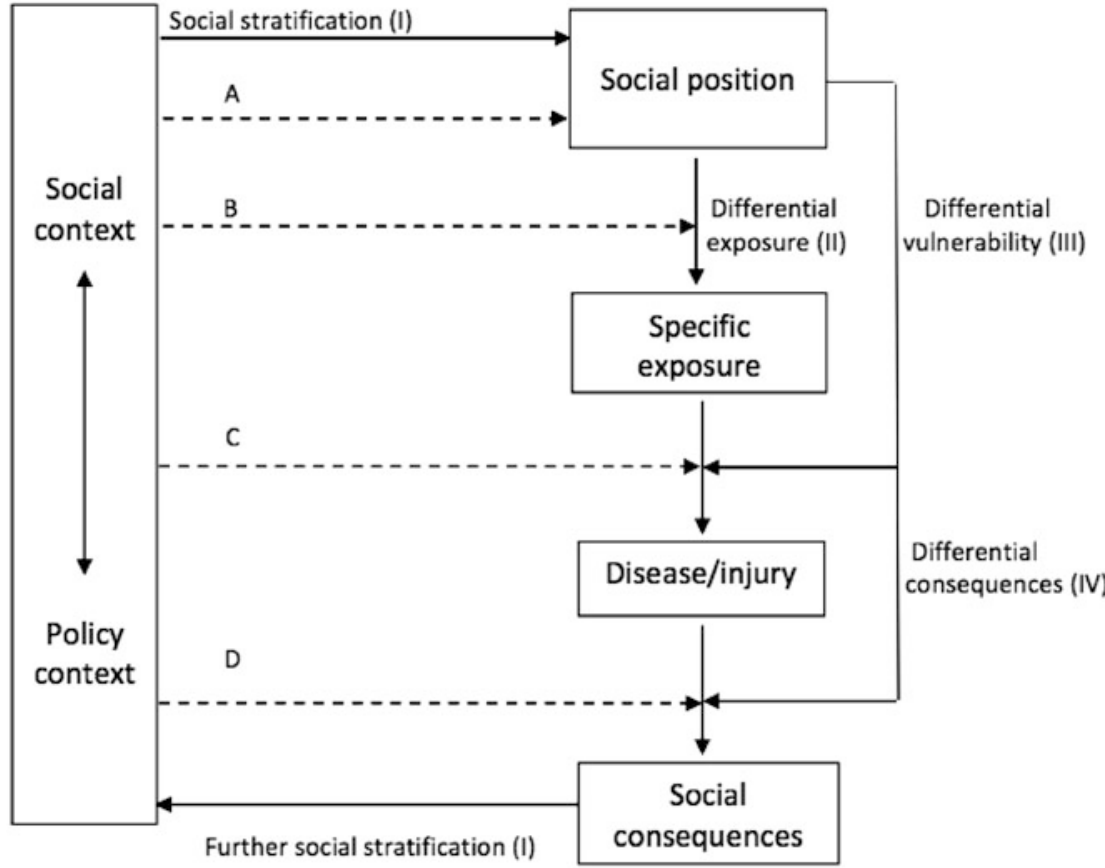

\section{Policy entry points:}

$A=$ modifying effect of social context and policy on social stratification;

$\mathrm{B}=$ policies affecting differential exposure;

$\mathrm{C}=$ policies affecting differential vulnerability;

$\mathrm{D}=$ policies affecting differential social consequences of disease.

Fig. 5.2 A conceptual model for studying the effect of social position and social context on health (Adapted from Diderichsen et al. 2001)

to health in the presence of high blood pressure (Capewell and Graham 2010)); and differential consequences of ill health (for example less advantaged groups who experience cardiovascular events are more likely to become unemployed than individuals in more advantaged positions (Holland et al. 2009)).

A key feature of the Diderichsen model is that it incorporates both social causation and social selection mechanisms within a common framework, across the life course. Importantly, the model also explicitly links the broader social environment to the causal pathway at the individual level and makes it clear that the social determinants of health are policy sensitive (Taylor-Robinson 2013).

Using the Diderichsen model, the studies outlined here explored how the clinical consequences of CF vary in the UK on the basis of SES across the life course, and 
how exposure to health damaging risk factors such as acquisition of important lung infections, and use of major CF treatment modalities vary over time.

A neglected area of study has been the effect of SES on social outcomes in CF, such as employment status. Understanding the social consequences of ill health is a key step in elucidating the pathways to health inequalities, since any adverse social outcomes that occur as a result of ill health can feedback and further damage health status. For example, ill health might lead to job loss, which can then have further adverse effects on health status, mediated by a range of physical and psycho-social mechanisms. Furthermore, there is evidence from social epidemiological studies to suggest that, in many settings, it is people from more disadvantaged backgrounds who particularly experience adverse health outcomes as a result of ill health - so called differential social consequences in the Diderichsen model (Milton et al. 2006; Holland et al. 2009; Carlsen et al. 2007, 2008).

\section{The Effect of Socioeconomic Status on Clinical Outcomes in Cystic Fibrosis in the UK}

In the UK studies, children with CF from more disadvantaged areas were shown to have worse growth and lung function trajectories compared with children from more affluent areas, but these inequalities did not widen with advancing age (Table 5.1). Looking at growth in the UK CF population in more detail, Fig. 5.3 shows clinically important differences for weight, height BMI on the basis of area deprivation. In a longitudinal analysis, adjusting for a range of confounding factors, the difference in weight and height standard deviation (SD) score is about one third between the most and least advantaged quintiles, whereas for BMI the difference is about one sixth of a standard deviation score (z-score). These results show that having $\mathrm{CF}$, and living in the most disadvantaged areas of the UK effectively doubles the nutritional disadvantage experienced by a person with CF. The deprivation gap in weight is greatest in the first few months of life, at the time of diagnosis, and there follows narrowing of the gap up to around age 3 from around -0.54 SD scores (95\% CI 0.73 to -0.34$)$ at birth to $-0.28(95 \% \mathrm{CI}-0.38$ to -0.18$)$ at age 3 , but then the gap remains constant into adulthood (Fig. 5.4).

The finding of a social gradient in growth outcomes, evident from around the time of diagnosis, points to important effects of deprivation in utero, and/or in the initial period prior to diagnosis. Both are plausible, but a limitation of studies thus far has been a lack of data on birth-weight, which would complete the picture. The association between low SES and low birth-weight, and length is well established in the general population (Spencer et al. 1999; Marmot et al. 2010; Howe et al. 2011, 2012). The causes for this are likely to be multi-factorial and relate to maternal health, including stress, diet, drug, alcohol and tobacco use during pregnancy (Marmot et al. 2010). The question remains, however, as to how having CF modifies this relationship. Direct comparison of the SES effect on 
Table 5.1 Summary of adjusted effects of deprivation on clinical outcomes and use of therapies in the paediatric and adult $\mathrm{CF}$ population in the UK

\begin{tabular}{|c|c|c|}
\hline & Age $<18$ & Age $18-40$ \\
\hline \multicolumn{3}{|l|}{ Clinical outcomes $^{\mathrm{a}}$} \\
\hline $\begin{array}{l}\text { Lung function as measured by } \\
\text { percent predicted forced } \\
\text { expiratory volume - } \% \mathrm{FEV}_{1}(\%)\end{array}$ & $-4 \cdot 12(-5 \cdot 01$ to $-3 \cdot 19)$ & $-1 \cdot 6(-4 \cdot 41$ to $1 \cdot 25)$ \\
\hline Weight-for-age (SD score) & $-0 \cdot 28(-0 \cdot 38$ to $-0 \cdot 18)$ & $-0 \cdot 31(-0 \cdot 46$ to $-0 \cdot 16)$ \\
\hline Height-for-age (SD score) & $-0 \cdot 31(-0 \cdot 40$ to $-0 \cdot 21)$ & $-0 \cdot 31(-0 \cdot 43$ to $-0 \cdot 19)$ \\
\hline BMI-for-age (SD score) & $-0 \cdot 13(-0 \cdot 22$ to $-0 \cdot 04)$ & $-0 \cdot 12(-0 \cdot 25$ to $0 \cdot 01)$ \\
\hline OR for $P$. aeruginosa colonisation & $1 \cdot 89(1 \cdot 34$ to $2 \cdot 66)$ & $1 \cdot 78(1 \cdot 26$ to $2 \cdot 51)$ \\
\hline \multicolumn{3}{|l|}{ Therapies } \\
\hline OR for any IV therapy ${ }^{b}$ & $2 \cdot 52(1 \cdot 92$ to $3 \cdot 17)$ & $1 \cdot 89(1 \cdot 51$ to $2 \cdot 38)$ \\
\hline $\begin{array}{l}\text { Mean difference IV days per year } \\
(\%)^{\mathrm{b}}\end{array}$ & $15 \cdot 9(8 \cdot 2$ to 24$)$ & $10 \cdot 6(2 \cdot 5$ to $19 \cdot 2)$ \\
\hline OR for supplemental feeding ${ }^{\mathrm{c}}$ & $1 \cdot 78(1 \cdot 42$ to $2 \cdot 2)$ & $2 \cdot 38(1 \cdot 69$ to $3 \cdot 36)$ \\
\hline OR for DNase therapy ${ }^{\mathrm{b}}$ & $0 \cdot 40(0 \cdot 21$ to $0 \cdot 72)$ & $0 \cdot 37(0 \cdot 26$ to $0 \cdot 52)$ \\
\hline OR for inhaled antibiotics ${ }^{\mathrm{c}}$ & $0 \cdot 66(0 \cdot 47$ to $0 \cdot 93)$ & $0 \cdot 40(0 \cdot 31$ to $0 \cdot 5)$ \\
\hline
\end{tabular}

Source: Adapted from Taylor-Robinson et al. (2013a)

All estimates compare the most deprived quintile to the least deprived (reference) quintile. $95 \%$ $\mathrm{CI}$ in parenthesis

${ }^{a}$ The outcomes are from separate longitudinal models adjusted for time trends, sex, genotype, screening status and ethnicity

${ }^{\mathrm{b}}$ Adjusted for time trends, sex, genotype, screening status, $\% \mathrm{FEV}_{1}$ and $P$. aeruginosa colonisation status

${ }^{\mathrm{c}}$ Adjusted for time trends, sex, genotype, screening status and BMI SD score

growth in the $\mathrm{CF}$ population, and the general population is challenging, due to the lack of studies using comparable SES measures and birth cohorts, and due to the effect of the obesity epidemic in the general population, whereby a relationship between overweight and low SES emerges from around age 4 onwards (Howe et al. 2011, 2012). This is in contrast to $\mathrm{CF}$, where children are consistently underweight compared to the UK reference population (Taylor-Robinson et al. 2013a). Further data on SES gradients in birth-weight in CF would clarify the extent to which the early growth differentials demonstrated are a reflection of the broader SES effects on birth-weight in the general population. The narrowing of inequality in weight SD score in the first 3 years of life is an important finding and suggests that diagnosis and treatment for CF in the NHS may be having a pro-poor, or 'levelling-up' effect on health inequalities. This has policy implications, and supports the universal screening that has been introduced in the UK to allow earlier diagnosis (TaylorRobinson 2013).

Lung function, as measured by percent predicted forced expiratory volume in one second $\left(\% \mathrm{FEV}_{1}\right)$ is considered one of the most important clinical outcomes in $\mathrm{CF}$, and Fig. 5.5 shows the differences between deprivation quintiles in the UK with respect to key respiratory outcomes. In an adjusted longitudinal analysis (Table 5.1), people from the most deprived areas had significantly worse lung function $(-4.12$ 

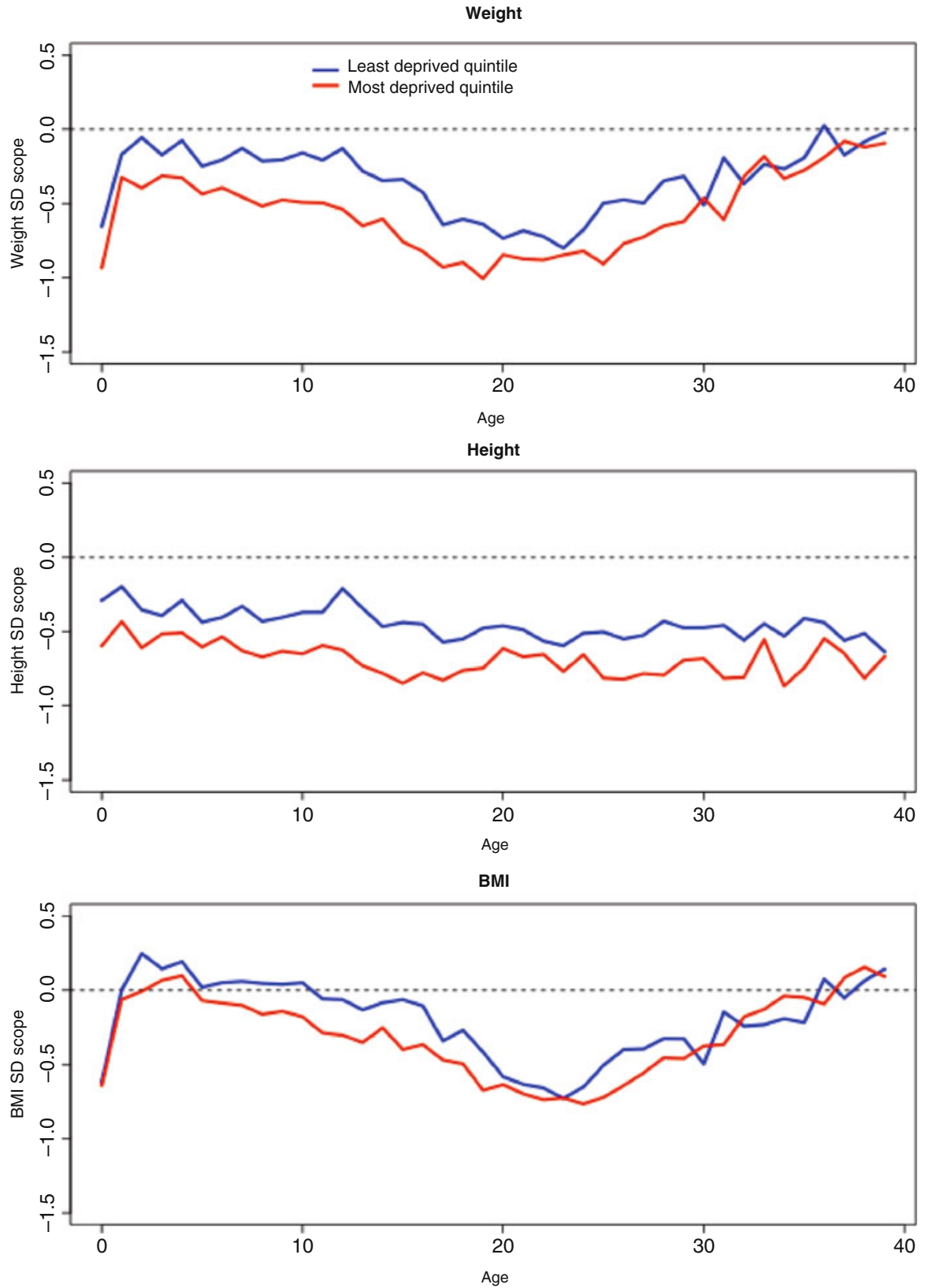

Fig. 5.3 Anthropometric outcomes: mean cross-sectional weight, height, and BMI by age comparing extremes of deprivation quintile (red most deprived) (Adapted from Taylor-Robinson et al. 2013a) 


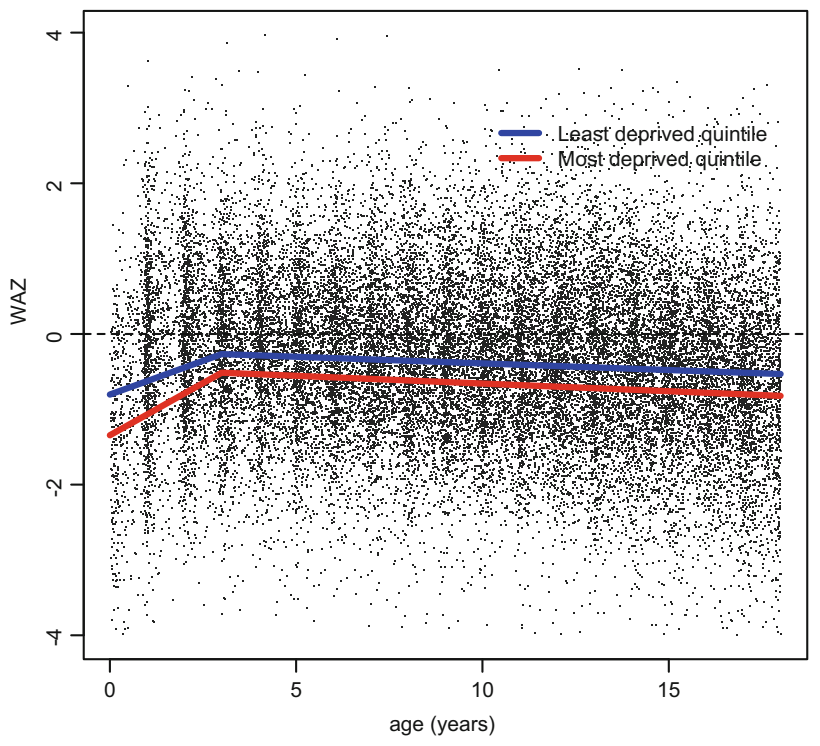

Fig. 5.4 Longitudinal weight trajectory in children in the UK with CF comparing extremes of deprivation quintile. Trajectories plotted at reference values for other covariates in the regression model: female sex, homozygote delta F508 carrier, not diagnosed by screening, white, born in 1991 (Adapted from Taylor-Robinson 2013)
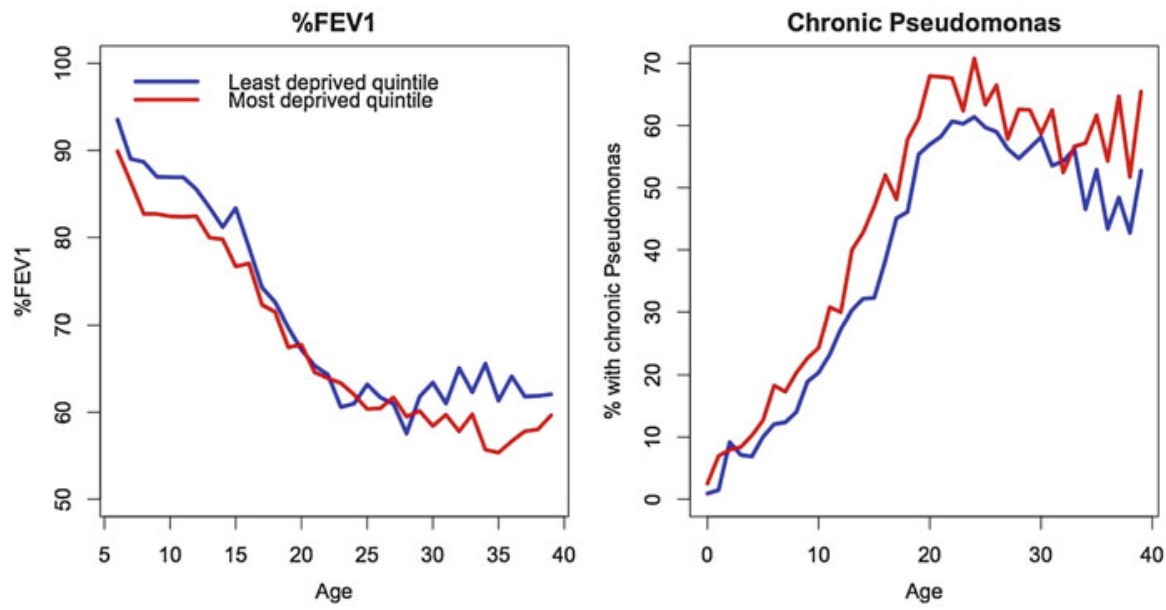

Fig. 5.5 Respiratory outcomes: mean cross-sectional $\% \mathrm{FEV}_{1}$ and $P$. aeruginosa colonization prevalence by age comparing extremes of deprivation quintile (Adapted from TaylorRobinson et al. 2013a) 
percentage points, $95 \% \mathrm{C} 1-5.01$ to -3.19$)$, but the deprivation gap in $\% \mathrm{FEV}_{1}$ did not increase over the paediatric age range. The prevalence of chronic P. aeruginosa colonisation, the key infection in $\mathrm{CF}$, is also higher in people from the most deprived areas of the UK, from an early age (OR 1.89 in the <18 age group, $95 \%$ CI 1.34 to 2.66) (Table 5.1).

The finding of a social gradient in lung function at age 5 in the UK, when it can be first measured on a routine basis, points to the influence of risk factors earlier in the life course. These are likely to include both environmental and healthcare factors. Schechter and colleagues' found that inequalities in $\% \mathrm{FEV}_{1}$ by Medicaid status widened slightly from 5 to 20 years of age (Schechter et al. 2001) in a cross sectional analysis. At round age 5 there was a gap of around $9 \%$ in $\% \mathrm{FEV} 1$ in the US population, whereas in another study O'Connor and colleagues found a difference of $5.5 \%$ between most and least deprived quintiles (O'Connor et al. 2003). Due to the methodological differences it is not possible to make a direct comparison between UK and US findings in terms of the magnitude of the deprivation gap in lung function (Taylor-Robinson 2013).

In the adult population, growth and P. aeruginosa outcomes were worse in the most deprived adults, but no significant difference in lung function was detected (Table 5.1). The lack of an association between SES and $\% \mathrm{FEV}_{1}$ in the adult population is perhaps surprising, given the tendency for social inequalities in health outcomes to increase over time. This may relate to the differences in the use of therapies across social groups described in the next section, or to factors relating to the CF registry, such as left-censoring, selective dropout due to death, and reduced power to detect effects in the adult age range due to the smaller numbers of individuals in the analysis (Taylor-Robinson 2013).

\section{The Effect of Socioeconomic Status on Treatment and Healthcare Use in the UK}

Use of IV antibiotic therapy for the treatment of respiratory infections, and clinical exacerbations is a major treatment modality in CF. Longitudinal analysis showed that people in the UK from more deprived areas are about twice as likely to receive IV antibiotics in a particular year, after adjustment for disease severity, on the basis of $\% \mathrm{FEV}_{1}$ and $P$. aeruginosa colonisation status (Odds ratio 2.52, $95 \%$ CI 1.923.17 in the $<18$ age group, and OR $1.89,95 \%$ CI 1.51-2.38 in the adult age group, comparing most to least deprived quintiles) (Table 5.1, Fig. 5.6). This apparent positive discrimination persists across the age range, from infancy up to 40 years of age. Furthermore if children and adults with $\mathrm{CF}$ are recorded as having any IV therapy in a particular year, then people from most deprived areas in the UK, compared to the least, are more likely to have more treatment days (more intensive treatment), after adjusting for disease severity (15.9\% more days in the paediatric age group, $95 \%$ CI 8.2-24, and $10.6 \%$ more days in the adult age group $95 \%$ 

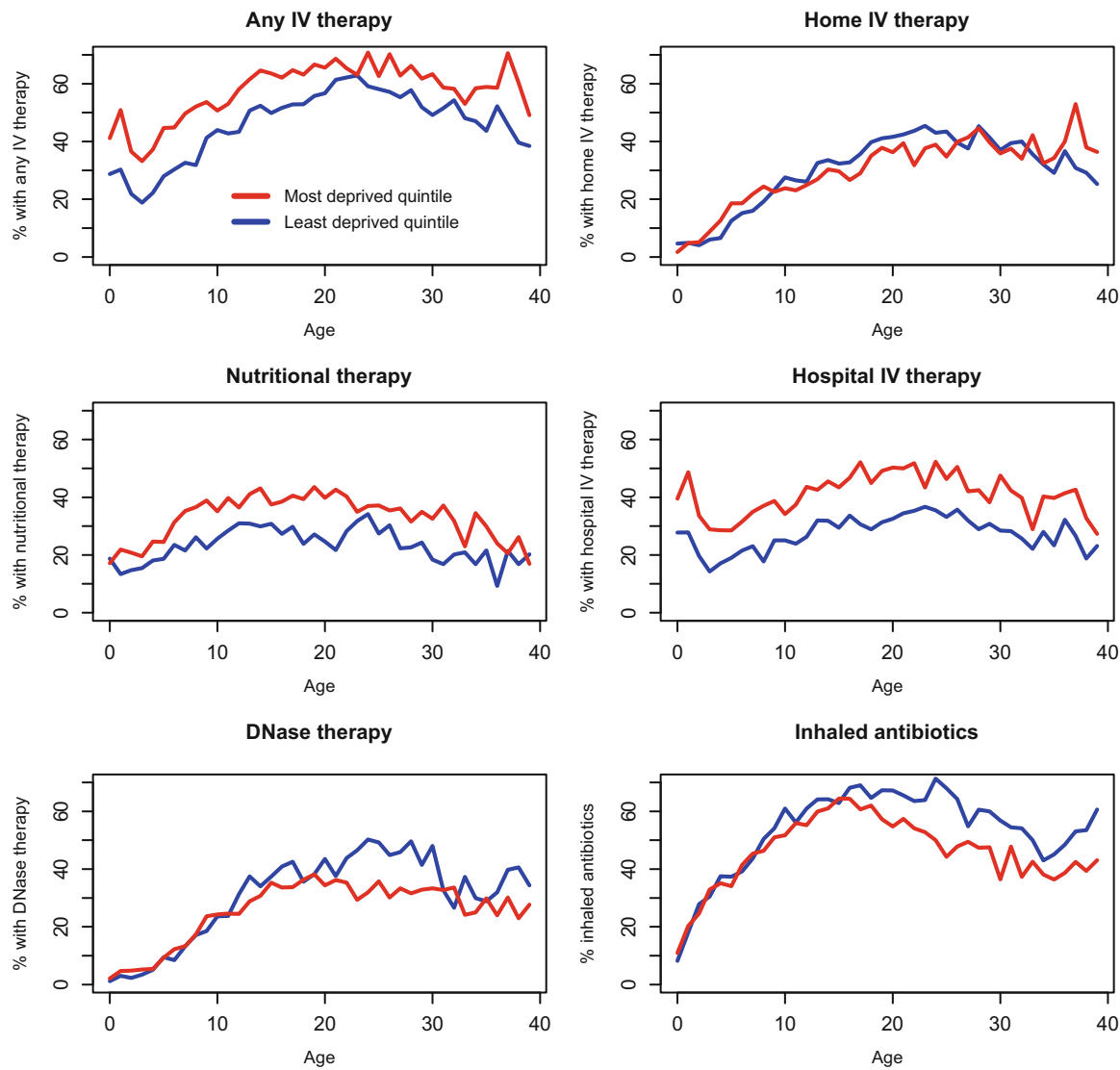

Fig. 5.6 Use of therapies: any IV antibiotic therapy, home IV antibiotic therapy, hospital IV antibiotic therapy, supplemental feeding, DNase, and inhaled antibiotics, by age comparing extremes of deprivation quintile (Source: Adapted from Taylor-Robinson et al. 2013a)

CI 2.5-19.2). Disaggregating the use of any IV antibiotics into use of therapies at home, and in hospital, demonstrated that the positive discrimination in use of any IV therapy was almost entirely due to delivery of these therapies in hospital, as opposed to home-based treatment. Overall, children from more affluent areas were more likely to be treated at home compared to their more disadvantaged counterparts (Fig. 5.6).

The picture is similar for nutritional therapies, with people from more deprived areas of the UK with CF being more likely to be treated with nutritional therapies, after adjustment for nutritional status, measured on the basis of BMI SD score (OR $1.78,95 \%$ CI $1.42-2.2$ in the $<18$ age group, and OR $2.38,95 \%$ CI 1.69-3.36 in the adult age group, comparing the most to the least deprived quintiles).

A different pattern is observed when it comes to use of long term inhaled therapies such as DNase and inhaled antibiotics. There was evidence of inequality 
in the delivery of inhaled therapies to the UK CF population, after adjusting for measures of disease severity (Table 5.1, Fig. 5.6). Furthermore, this association becomes stronger in the adult age range. In children, there was no association between DNase use and deprivation, prior to adjustment for disease severity. However, after adjustment for disease severity, there was an apparent inequality, suggesting that DNase may not be delivered equitably in children. This analysis was clear in the adult population in both the unadjusted and adjusted associations, with adults from more affluent areas being more likely to report using DNase or inhaled antibiotics in the preceding year.

With regard to the major treatments for CF, the UK studies provide evidence of more intensive treatment being delivered to both children and adults with $\mathrm{CF}$, for two major pillars of CF care - treatment with IV therapies, and nutritional therapies after adjusting for measures of disease severity. These findings provide evidence of a so-called 'pro-poor' bias (Ravallion 2001). Aside from the possibility of residual confounding by severity, one explanation for these findings is that clinicians in the UK are actively taking steps to address, and overcome the perceived excess disadvantage faced by people living in more deprived areas. This may be particularly the case with regard to paediatric care which may be delivered more intensively, and in a hospital setting, to children with $\mathrm{CF}$ who are perceived to be living in more disorganised home circumstances, where there may be additional barriers to ensuring that they receive the care and treatments needed (Gupta et al. 2009). More intensive delivery of treatment to more disadvantaged children may further play a role in the reduction in weight inequality over the first few years of life, and the relatively stable inequalities gap demonstrated in the UK studies, as opposed to a finding of increasing inequality.

\section{Longitudinal Employment Status in People with CF}

People with chronic illnesses face numerous barriers to entering the labour market, and CF provides a case in point. Factors related to disease severity, such as reduced lung function may restrict employment choices for adults with $\mathrm{CF}$, and the treatment burden further compounds this; adults with $\mathrm{CF}$ are generally expected to perform physiotherapy regularly and there are the added demands of taking large numbers of therapies, including frequent visits to hospital (Sawicki et al. 2009).

The analysis of the UK Registry shows that at any one time, about $50 \%$ of the UK CF population was recorded as being in full or part-time employment for all ages, but patterns differed by age, sex, and deprivation status. In a longitudinal analysis, all other things being equal, people from more disadvantaged areas in the UK were less likely to be in employment, and furthermore, social deprivation was found to modify the effect of disease severity in CF: poor lung function, as measured by lower lung function $\left(\% \mathrm{FEV}_{1}\right)$, is more harmful to employment chances for people living in the most disadvantaged circumstances compared to the least (Fig. 5.7, Table 5.2). A fall in lung function in people with CF has more of an effect on employment 

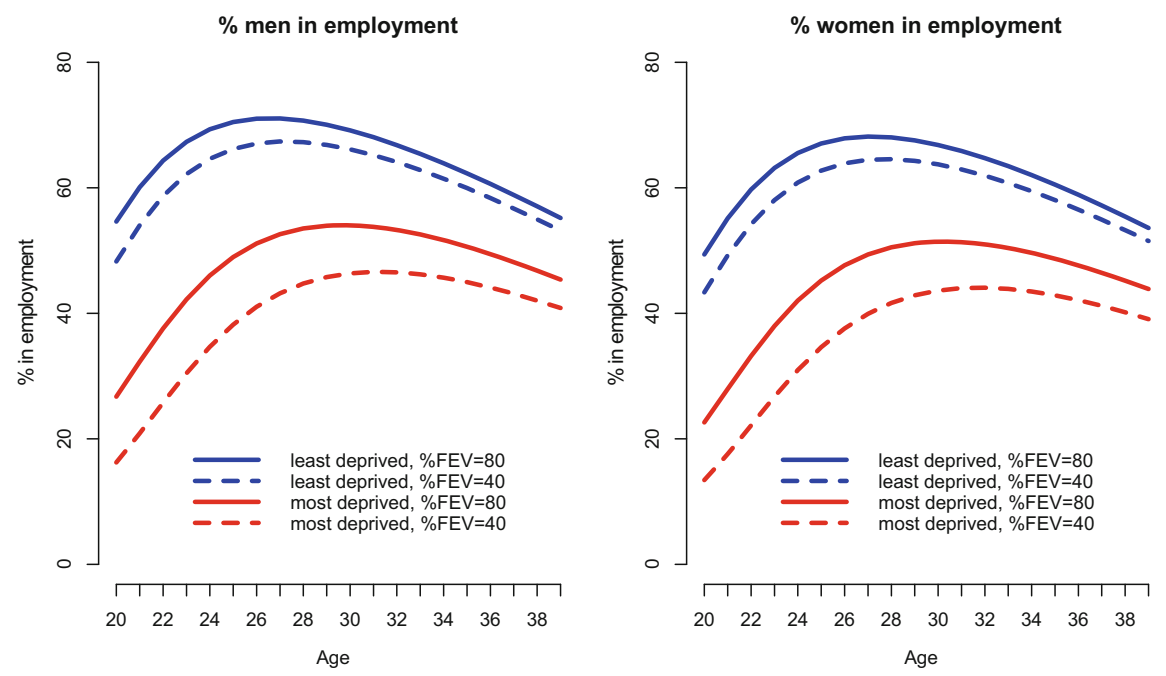

Fig. 5.7 Longitudinal employment trajectory versus age, demonstrating the interaction between deprivation and $\% \mathrm{FEV}_{1}$. The lines show the final modelled longitudinal contrasting the adjusted effects of deprivation, and $\% F E V_{l}$. Low $\% F E V_{l}$ is more damaging to employment chances in people living in the most disadvantaged areas. Other covariates in the final model are fixed (Adapted from Taylor-Robinson et al. 2013b)

Table 5.2 Percentage of people with CF in employment at age 30

\begin{tabular}{l|l|l}
\hline & Employment (\%) & Employment (\%) \\
\cline { 2 - 3 } & Men & Women \\
\hline $\begin{array}{l}\text { No health or social disadvantage } \\
\text { (good lung function and high SES) }\end{array}$ & $69 \cdot 2$ & $66 \cdot 8$ \\
\hline $\begin{array}{l}\text { Health disadvantage only (poor } \\
\text { lung function and high SES) }\end{array}$ & $66 \cdot 1$ & $63 \cdot 7$ \\
\hline $\begin{array}{l}\text { Social disadvantage only (good } \\
\text { lung function and low SES) }\end{array}$ & $54 \cdot 1$ & $51 \cdot 4$ \\
\hline $\begin{array}{l}\text { Double disadvantage (poor lung } \\
\text { function and low SES) }\end{array}$ & $46 \cdot 4$ & $43 \cdot 6$ \\
\hline Adapted fom Taylor-Robin
\end{tabular}

Adapted from Taylor-Robinson (2013)

$\% \mathrm{FEV}_{1}$ fixed at 80 percentage points for good lung function, and 40 percentage points for poor lung function

High SES fixed at least deprived quintile, and low SES fixed at most deprived quintile

chances in disadvantaged populations - at the age of 30 , a contrast of 40 percentage points in lung function corresponds to a decline in employment prevalence from 69.2 to $66.1 \%$ (3.1 percentage points difference) for men in least deprived quintile, compared to a change from 54.1 to $46.4 \%$ ( 7.7 percentage points difference) in the most deprived quintile (Table 5.2).

The social consequences of having a chronic disease such as $\mathrm{CF}$ are important, and understudied. Although social conditions do not influence the risk of having CF, 
there are significant differences in outcomes such as growth and lung function, and ultimately survival, in people with CF in the UK and US (Taylor-Robinson et al. 2013a; Schechter et al. 2001; Barr and Fogarty 2011). The analysis of UK data presented here suggests that people with the double burden of chronic illness and low SES are more likely to be excluded from the labour market. This in turn is likely to lead to an increased risk of poverty, social exclusion, and further adverse effects on health. In this way, the differential social consequences of illness in the context of CF, represents an important pathway for the amplification of health inequalities over the life course (Taylor-Robinson et al. 2013b).

\section{Social Inequalities, Even for Genetic Diseases}

The analyses of the UK CF registry presented here demonstrate that people from more disadvantaged areas in the UK have worse health and social outcomes than their more affluent counterparts. They are more likely to have poor growth, poorer lung function, and to acquire $P$. aeruginosa, and are less likely to be in employment. In contrast, the use of major therapies in the UK CF population shows a so called 'pro-poor' bias, with people living in the most deprived areas of the UK around twice as likely to be treated with IV antibiotics and nutritional therapies, after adjusting for disease severity. However, there was evidence of inequalities in the use of home IV therapies, DNase, and inhaled antibiotics. With regard to employment outcomes the analyses demonstrate that deprivation modifies the effect of disease severity in CF: poor lung function is more harmful to employment chances for people living in the most disadvantaged circumstances compared to the least.

$\mathrm{CF}$ is the archetypal classically inherited genetic disease, caused by a single gene defect that is both a necessary and sufficient cause of a chronic illness. CF was one of the first diseases for which the precise genetic mechanism was elucidated, with the sequencing of the CFTR gene, and yet knowledge of the genetic mutation does not predict clinical outcome (Kerem et al. 1990; Schechter 2004). Despite the genetic origin of $\mathrm{CF}$, the evidence presented here shows that outcomes in $\mathrm{CF}$ are socially patterned, demonstrating that social factors are leading to profound differences in the course of the illness, which cannot be explained by genetic differences.

\section{Inequalities from the Start}

The finding that inequalities start early in the life course for people with $\mathrm{CF}$ and then track through until later life, even for a genetic disease like CF, supports the growing evidence around the early origins of health inequalities. The convergence between the inequalities literature, and the current direction of CF research is also 
striking, whereby both disciplines are suggesting that the early years are critical. In their recent piece on early lung disease, for instance, Grasemann and Ratjen state (Greasemann and Ratjen 2013):

The infant and preschool age could represent a unique period of opportunity to postpone or even prevent the onset of cystic fibrosis lung disease.

Compare this to possibly the key recommendation of the UK Marmot review (Marmot et al. 2010):

Action to reduce health inequalities must start before birth and be followed through the life of the child. Only then can the close links between early disadvantage and poor outcomes throughout life be broken.

The findings presented here support the growing consensus that early disadvantage tracks forward, to influence adult health in later life, and that children who start behind tend to stay behind (Marmot et al. 2010; Kuh et al. 2004; Galobardes et al. 2008). This has important implications for public health policy, and suggests that children may have optimum or sub-optimum trajectories on the basis of early life experiences. As Fig. 5.8 below illustrates, these early life trajectories can determine the point at which an individual becomes symptomatic for a particular adult chronic disease. Interventions to targeted in the early years may delay the onset of limiting illness in later life.

The Y-axis in Fig. 5.8 represents some general phenomena relating to health development. For instance, this model has been applied to the development of lung health (Kuh et al. 2004), mental health capacity (Kirkwood et al. 2008), and features in a recent Lancet paper in a very similar form with 'behavioural competence' on the Y-axis (Walker et al. 2011).

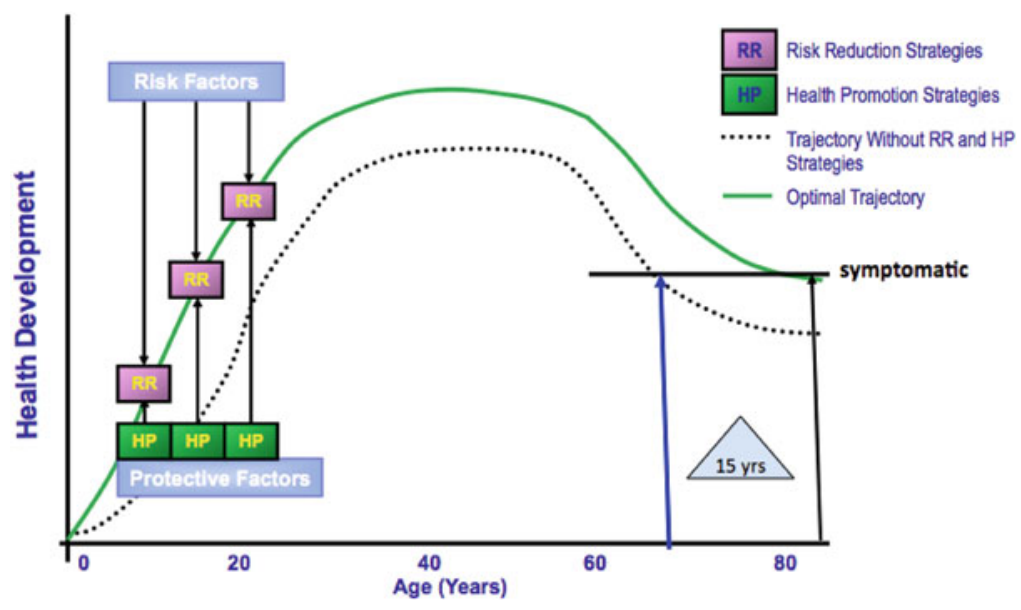

Fig. 5.8 How risk reduction and health promotion strategies influence health development (Adapted from Halfon et al. 2000) 


\section{Health Services and Heath Inequalities in CF}

The findings presented here have demonstrated variations in the recorded use of treatments by SES for people with CF in the UK NHS. What do these findings tell us more broadly about the role of health services and their role in mitigating or potentiating health inequalities?

An important starting point is to understand what equity in healthcare might look like? Restating Margaret Whitehead's definition, equity in healthcare can be seen as being multifaceted and incorporating ideas about: fair arrangements that allow equal geographic, economic and cultural access to available services for all in equal need of care. The end goal of equity in health care would be to closely match services to the level of need. This may very well result in large differences in access and use of services between different socioeconomic groups, favouring the more disadvantaged groups in greatest need (Whitehead and Dahlgren 2007).

Need, in the context of the definition above, can be taken to relate not just to disease severity, but also to disadvantage. On this basis one can argue that equity is being achieved for certain aspects of CF care in the NHS, since the data suggests that clinicians are responding to both disease severity, and level of disadvantage when making treatment decisions.

The Commission on Social Determinants of Health highlights that inequitable delivery of health care is an important factor in the generation of health inequalities (CSDH 2008). Whilst health services are generally not the cause of health inequalities (Marmot et al. 2010), they can play an important role in the amplification and perpetuation of disadvantage in a number of ways, for example through the so-called 'inverse care law' (Hart 1971) or the 'medical poverty trap' in health care systems that are not free at the point of access (Whitehead et al. 2001). The famous inverse care law, described by the British GP Tudor Hart (Hart 1971) states:

The availability of good medical care tends to vary inversely with the need for it in the population served. This inverse care law operates more completely where medical care is exposed to market forces, and less so where such exposure is reduced.

This describes the situation whereby those who most need high quality health care, end up receiving less and/or lower quality care. For this reason, striving for equity in health service delivery, as defined by equal use for equal need (Whitehead and Dahlgren 2007), is a central principle for health care systems (Whitehead 1990), including in the NHS.

In the UK, the Darzi report noted the relationship between low SES and poor health and suggested that the NHS has a pivotal role in providing excellent services as "a matter of fairness" (Darzi 2008). The controversial new Health and Social Care Act further enshrines in legislation explicit duties on the Secretary of State, NHS Commissioning Board and clinical commissioning groups (CCGs) to have regard to the need to reduce inequalities in access to, and to the outcomes of healthcare (DH 2012). Many dissenting voices have suggested the legislation is likely to have significant adverse effects on health inequalities (FPH 2010; Pollock et al. 2012a, b; Whitehead et al. 2010). While this may well be the case, the 
wording of the legislation could serve as a lever to hold those responsible for health services to account in terms of taking action to reduce inequalities in outcomes. In these troubled times for the NHS in the UK, the findings presented here provide some evidence that the system of care in CF can take into account the extra needs of disadvantaged children and their families in the UK to deliver care that may be effective in reducing, or at least limiting an increase in health inequalities.

The analysis also sheds some light on potential differences between the delivery of chronic care for children versus that delivered to adults, by demonstrating an increasing propensity to inequality in delivery of both inhaled CF treatments in the adult population, as compared to the paediatric age group. This corroborates the broader literature, in terms of access to and use of care in chronic diseases, which suggests a different picture in adults and children: In adults, a systematic review of universal health care systems by Hanratty et al. suggested a decline in need adjusted use with increasing deprivation, especially in use of specialist hospital services, but reasonably equitable access to primary health care (Hanratty et al. 2007). A more recent European study found large inequalities in the utilisation of specialist care for chronic diseases, which were not compensated by utilisation of GP services (Stirbu et al. 2011). The analysis of CF Registry data from the UK demonstrated a mixed picture for adults, with marked pro-poor bias for IV and nutritional therapies, but inequality in the use of inhaled therapies.

This contrasts with analyses of children's use of health services in the UK, where the studies have tended to show increased use with lower SES, and arguably equitable delivery of care in the studies that have adjusted for need, notwithstanding the difficulties of undertaking precise adjustment. Cooper et al. found no evidence that children and young people's use of health services varied according to their SES, in an analysis that adjusted for need on the basis of self-reported health status, a rather crude measure, in an analysis of the British General Household survey (Cooper et al. 1998). Saxena et al. demonstrated increased use of primary care for disorders such as infections, asthma, and injuries and poisonings in children with lower SES (Saxena et al. 1999). In a further study by the same author, children's use of primary and secondary health services reflected health status rather than SES, and on this basis the authors suggest that equity of access has been partly achieved (Saxena et al. 2002). A more recent study in the UK demonstrated a clear association between adverse socioeconomic position at the time of birth and increased hospital inpatient admissions, days, and costs during the first 10 years of life (Petrou and Kupek 2005). A further study of children in Nordic countries demonstrated equitable access to primary care, but inequality in use of specialist hospital services after careful adjustment for health status on the basis of questionnaire data (Halldorsson et al. 2002).

It remains unclear whether the increasing inequality observed in use of inhaled treatments in $\mathrm{CF}$ in adults reflects general differences between paediatric and adult care for chronic disease, or is specific to differences in the CF model of care, perhaps explained by the potential for paediatricians to act in a more paternalistic manner towards the children in their care, in contrast to the relationship between an adult 
patient and the CF care team, where adult patients can 'vote with their feet'. Further studies should focus on identifying aspects of CF care in children, and adulthood that may be important in reducing health inequalities.

\section{What Are the Implications for Policy and Clinicians?}

For individual clinicians, social deprivation needs to be considered as a major risk factor for poor outcomes in $\mathrm{CF}$, and appropriate responses to remediate against the adverse effects of deprivation should be developed. An important first step is to acknowledge and measure the problem. Without on-going data collection to monitor health inequalities, there can be no policy response.

There are a number of steps that could be taken to influence differential exposures. One obvious target for action is to protect newly diagnosed children from environmental tobacco smoke exposure (ETS), since this may be the single most important explanatory factor for SES-related inequalities in this disease (TaylorRobinson and Schechter 2011). Early identification of family members who smoke, collection of that data in the registry, and appropriate counselling and referral to smoking cessation services would be an effective intervention for all patients regardless of social position.

The UK analysis presented in this chapter also suggests differential exposure to $P$. aeruginosa acquisition, and this requires further investigation. One concern is that this may relate to hospital-acquired acquisition of $P$. aeruginosa, from other patients with $\mathrm{CF}$, as a result of more time spent in hospital. An appropriate policy response might be to ensure that mechanisms are put in place to facilitate equitable delivery of treatments at home, wherever possible. Home care has been shown to be as effective as hospital treatment for some patients (van Aalderen et al. 1995), but not others (Bosworth and Nielson 1997; Thornton et al. 2005). It is also less expensive and may be associated with improvement in quality of life (van Aalderen et al. 1995). Access to appropriate home care may also mean that children are less likely to miss school, which is important in terms of reducing the differential consequences of ill health.

There are some further steps that individual clinicians and teams could take to reduce children's exposure to poverty, and its consequences. Whilst beyond the scope of full discussion here, an increased focus on a whole family approach to the care of the child with $\mathrm{CF}$, with appropriate involvement of the full range of social services support available to children and families living in disadvantaged circumstances, may help to mitigate some of the effects of social deprivation. This would include supporting parents to access all the benefits and services that they are entitled to, and working to reduce any perceived stigma associated with using these services. Support with the additional costs of childcare, travel to clinic appointments, and any additional medical expenditure would also help reduce the financial burden on the most disadvantaged families. This should be coupled with support to develop patient and family disease self-management skills (Smith and Goldman 2010; Goldman and Smith 2002). 
Social workers, and other members of the multidisciplinary CF team have an important role in helping people with CF navigate the welfare system, so that they are clear about the benefits that they are entitled to, and the support available to help people with chronic illness in the workplace. This is particularly important at the moment, in the context of the widespread changes to the welfare and benefits system in the UK, with the drive to reduce the number of people claiming Disability Living Allowance. A recent study by Nash et al. demonstrated that the majority of adult patients with CF claim some benefits, and the majority of these were concerned about the planned reforms (Nash et al. 2011). Furthermore, the concerns of the CF community regarding the changes to the welfare system were outlined in a submission by the CF Trust to the Department of Work and Pensions (2011). Further efforts are required to identify effective workplace, rehabilitation, and other interventions to reduce the employment disadvantage experienced by people with $\mathrm{CF}$, particularly for those from more disadvantaged areas.

A key question for practicing physicians raised by our studies is what role health care delivery plays in mitigating or potentiating health inequalities in CF. In the $\mathrm{UK}$, we have demonstrated a mixed picture, and action is required to understand the inequalities in access to inhaled therapies uncovered, and to promote the pro-poor delivery of care demonstrated for other treatments, that may be effective in limiting increases in outcome inequality over time. The potential utility of systematically targeting more intensive therapy at children living in disadvantaged circumstances should be investigated further (Gupta et al. 2009). The adoption of system-based methods to optimize consistency in the use of best care practices might help further minimize variations in prescribed care (Schechter et al. 2009). Furthermore, the early appearance of inequalities, and the potential for decreasing inequality in weight in the first few years of life, focusses policies on the early years, and provides support for new-born screening programmes in CF.

Ultimately, however, while individually focussed interventions may be of some limited success, the long term solution to health inequalities in people with $\mathrm{CF}$ and in the general population is likely to be one that takes broader action to address the "social determinants of health" (CSDH 2008). These are the "conditions in which we are born, grow up, work and live", and include income and income distribution, education, employment and working conditions, housing, food insecurity, race/ethnicity, and gender roles. These factors provide a particularly important context for a family dealing with the stresses of caring for a child with a complex chronic illness like CF over a lifetime. The evidence is clear, unfortunately, that we have made little progress over the last few decades in reducing health inequalities (Marmot et al. 2010). However, the analysis presented in this chapter provides further evidence that the early years represent the key period for targeting interventions to reduce inequalities. An important place to start would be to renew efforts in the UK to reduce children's exposure to poverty, by for instance (Marmot et al. 2010):

- maximising household incomes, by helping parents into employment;

- providing affordable housing; 
- providing affordable, high quality child care;

- providing affordable public transport;

- helping families manage debt;

- providing better social security support for families caring for children with chronic illness.

With reference to Fig. 5.8 above, policy makers should also act to reduce any inequitable distribution of health damaging and health promoting exposures over the course of children's lives. Reducing the consequences of poverty by focussing on child development in the early years is a good place to start. Actions could involve (Marmot et al. 2010; Field 2010):

- protecting investment in the early years in the face of budget cuts in the UK;

- shifting expenditure towards the early years wherever possible;

- providing high quality and consistent support and services for parents during pregnancy;

- providing high quality universal services in childhood;

- supporting families to achieve progressive improvements in early child development, by providing good quality early years education and childcare;

- providing support so that all children can access a healthy diet in the early years;

- providing high quality home visiting services;

- focussing on narrowing the educational attainment gap at all stages.

As health deteriorates, the ability of people to remain in education and employment declines. Being out of work increases the risk of poverty and social exclusion, and is likely to further damage the health of the most disadvantaged. Actions to address differential social consequences could include (Holland et al. 2011):

- supporting people with chronic illness to find appropriate employment, with a focus on active labour market policies;

- providing better in-work social security support for people with chronic illness.

\section{Conclusions}

$\mathrm{CF}$ is the commonest serious inherited disease among Caucasian populations. Intensive support from family and health care services is needed from the time of diagnosis onwards, and most patients die prematurely from respiratory failure. There have been astounding improvements in survival over successive birth cohorts in CF, such that it is estimated that British children born in the twenty-first century will have a median survival of over 50 years of age (Dodge et al. 2007). However, there remains a great deal of variation in disease progression and survival in $\mathrm{CF}$, much of which is related to social and environmental rather than genetic determinants (Schechter 2004). Most pointedly, it has been known for over 20 years (Britton 1989) that people with CF from socio-economically disadvantaged backgrounds die younger than those in more advantaged positions. 
CF offers a valuable case for understanding how health inequalities develop. It is an autosomal recessive disease with an asymptomatic (and, until recently, undetectable) carrier state, so unlike many other diseases, SES does not influence who gets CF. SES-related outcome inequalities develop due to the different patterns of exposure to harmful and protective or therapeutic influences over the course of people's lives. Studies from the US and UK show that significant inequalities in key intermediate CF outcomes such as growth and lung function begin early in childhood (Taylor-Robinson et al. 2013a; Schechter et al. 2001; O'Connor et al. 2003) and then persist over time. The early appearance and persistence of inequalities supports the need for interventions that are targeted at the early (and perhaps prenatal) years.

Open Access This chapter is distributed under the terms of the Creative Commons Attribution Noncommercial License, which permits any noncommercial use, distribution, and reproduction in any medium, provided the original author(s) and source are credited.

\section{References}

Adler, A. I., Shine, B. S., Chamnan, P., Haworth, C. S., \& Bilton, D. (2008). Genetic determinants and epidemiology of cystic fibrosis-related diabetes: Results from a British cohort of children and adults. Diabetes Care, 31(9), 1789-1794. doi: dc08-0466 [pii] 10.2337/dc08-0466.

Barr, H. L. S. A., \& Fogarty, A. W. (2011). The association between socioeconomic status and gender with median age at death from cystic fibrosis in England and Wales: 1959 to 2008. British Medical Journal, 343, d4662.

Barr, B., Taylor-Robinson, D., \& Whitehead, M. (2012). Impact on health inequalities of rising prosperity in England 1998-2007, and implications for performance incentives: Longitudinal ecological study. British Medical Journal, 345, e7831. doi:10.1136/bmj.e7831.

Bosworth, D. G., \& Nielson, D. W. (1997). Effectiveness of home versus hospital care in the routine treatment of cystic fibrosis. Pediatric Pulmonology, 24(1), 42-47.

Britton, J. R. (1989). Effects of social class, sex, and region of residence on age at death from cystic fibrosis. British Medical Journal, 298(6672), 483-487.

Capewell, S., \& Graham, H. (2010). Will cardiovascular disease prevention widen health inequalities? PLoS Medicine, 7(8), e1000320. doi:10.1371/journal.pmed.1000320.

Carlsen, K., Dalton, S. O., Frederiksen, K., Diderichsen, F., \& Johansen, C. (2007). Are cancer survivors at an increased risk for divorce? A Danish cohort study. European Journal of Cancer, 43(14), 2093-2099.

Carlsen, K., Dalton, S. O., Diderichsen, F., Johansen, C., \& Danish Cohort, S. (2008). Risk for unemployment of cancer survivors: A Danish cohort study. European Journal of Cancer, 44(13), 1866-1874. doi:10.1016/j.ejca.2008.05.020.

CF Trust. (2013). CF registry - annual data reports. http://www.cysticfibrosis.org.uk/about-cf/ publications/cf-registry-reports.aspx. Accessed 25 Apr 2013.

Cooper, H., Smaje, C., \& Arber, S. (1998). Use of health services by children and young people according to ethnicity and social class: Secondary analysis of a national survey. British Medical Journal, 317(7165), 1047-1051.

CSDH. (2008). Closing the gap in a generation: Health equity through action on the social determinants of health. Final report of the commission on social determinants of health. http:// whqlibdoc.who.int/publications/2008/9789241563703_eng.pdf. Accessed 29 Aug 2008. 
Darzi, A. R. (2008). High quality care for all: NHS next stage review final report. London: Department of Health.

Davies, J. C., Alton, E., \& Bush, A. (2007). Clinical review: Cystic fibrosis. British Medical Journal, 335(7632), 1255.

Department of Work and Pensions. (2011). Disability living allowance reform - submission by the Cystic Fibrosis Trust. http://www.dwp.gov.uk/docs/dla-reform-cystic-fibrosis-trust.doc. Accessed 25 Apr 2013.

DH. (2012). Reducing health inequalities - The health and social care act 2012. http://www.gov. uk/government/uploads/system/uploads/attachment_data/file/138267/C2.-Factsheet-Tacklinginequalities-in-healthcare-270412.pdf. Accessed 12 Apr 2013.

Diderichsen, F., Evans, T., \& Whitehead, M. (2001). The social origins of disparities in health. In T. Evans, M. Whitehead, F. Diderichsen, A. Bhuiya, \& M. Wirth (Eds.), Challenging inequities in health (pp. 12-23). New York: Oxford University Press.

Dodge, J. A., Lewis, P. A., Stanton, M., \& Wilsher, J. (2007). Cystic fibrosis mortality and survival in the UK: 1947-2003. European Respiratory Journal, 29(3), 522-526.

Field, F. (2010). The foundation years: Preventing poor children becoming poor adults. London: The Stationery Office/Tso.

FPH. (2010). FPH calls on government to withdraw health and social care bill 'in best interests of everyone's health'. http://www.fph.org.uk/fph_calls_on_government_to_withdraw_health_ and_social_care_bill_IT1\textquoteleftin_best_interests_of_everyonelT1 1 textquoterights_ health\T1\textquoteright. Accessed 12 Mar 2013.

Fuchs, H. J., Borowitz, D. S., Christiansen, D. H., Morris, E. M., Nash, M. L., Ramsey, B. W., Rosenstein, B. J., Smith, A. L., \& Wohl, M. E. (1994). Effect of aerosolized recombinant human DNase on exacerbations of respiratory symptoms and on pulmonary function in patients with cystic fibrosis. The Pulmozyme Study Group. New England Journal of Medicine, 331(10), 637-642. doi:10.1056/NEJM199409083311003.

Galobardes, B., Lynch, J. W., \& Smith, G. D. (2008). Is the association between childhood socioeconomic circumstances and cause-specific mortality established? Update of a systematic review. Journal of Epidemiology and Community Health, 62(5), 387-390. doi:10.1136/jech.2007.065508.

Goldman, D. P., \& Smith, J. P. (2002). Can patient self-management help explain the SES health gradient? Proceedings of the National Academy of Sciences of the United States of America, 99(16), 10929-10934. doi:10.1073/pnas.162086599.

Greasemann, H., \& Ratjen, F. (2013). Early lung disease in cystic fibrosis. The Lancet Respiratory Medicine, 1(2), 148-157.

Gupta, A., Urquhart, D., \& Rosenthal, M. (2009). Marked improvement in cystic fibrosis lung disease and nutrition following change in home environment. Journal of the Royal Society of Medicine, 102(Suppl 1), 45-48. doi:10.1258/jrsm.2009.s19010.

Halfon, N., Inkelas, M., \& Hochstein, M. (2000). The health development organization: An organizational approach to achieving child health development. The Milbank Quarterly, 78(3), 447-497. 341.

Halldorsson, M., Kunst, A. E., Kohler, L., \& Mackenbach, J. P. (2002). Socioeconomic differences in children's use of physician services in the Nordic countries. Journal of Epidemiology and Community Health, 56(3), 200-204.

Hanratty, B., Zhang, T., \& Whitehead, M. (2007). How close have universal health systems come to achieving equity in use of curative services? A systematic review. International Journal of Health Services, 37(1), 89-109.

Hart, J. T. (1971). The inverse care law. Lancet, 1(7696), 405-412.

Holland, P., Burstrom, B., Moller, I., \& Whitehead, M. (2009). Socioeconomic inequalities in the employment impact of ischaemic heart disease: A longitudinal record linkage study in Sweden. Scandinavian Journal of Public Health, 37(5), 450-458. doi:10.1177/1403494809106501. 
Holland, P., Burstrom, B., Whitehead, M., Diderichsen, F., Dahl, E., Barr, B., Nylen, L., Chen, W. H., Thielen, K., van der Wel, K. A., Clayton, S., \& Uppal, S. (2011). How do macro-level contexts and policies affect the employment chances of chronically ill and disabled people? Part I: The impact of recession and deindustrialization. International Journal of Health Services, 41(3), 395-413.

Howe, L. D., Tilling, K., Galobardes, B., Smith, G. D., Ness, A. R., \& Lawlor, D. A. (2011). Socioeconomic disparities in trajectories of adiposity across childhood. International Journal of Pediatric Obesity, 6(2-2), e144-e153. doi:10.3109/17477166.2010.500387.

Howe, L. D., Tilling, K., Galobardes, B., Smith, G. D., Gunnell, D., \& Lawlor, D. A. (2012). Socioeconomic differences in childhood growth trajectories: At what age do height inequalities emerge? Journal of Epidemiology and Community Health, 66(2), 143-148. doi: jech.2010.113068 [pii] 10.1136/jech.2010.113068.

Kerem, E., Corey, M., Kerem, B. S., Rommens, J., Markiewicz, D., Levison, H., Tsui, L. C., \& Durie, P. (1990). The relation between genotype and phenotype in cystic fibrosis-analysis of the most common mutation (delta F508). New England Journal of Medicine, 323(22), 15171522. doi:10.1056/NEJM199011293232203.

Kirkwood, T., Bond, J., May, C., McKeith, I., \& Teh, M. (2008). Foresight mental capital and wellbeing project. Mental capital through life: Future challenges. London: Government Office for Science.

Konstan, M. W., Butler, S. M., Wohl, M. E., Stoddard, M., Matousek, R., Wagener, J. S., Johnson, C. A., \& Morgan, W. J. (2003). Growth and nutritional indexes in early life predict pulmonary function in cystic fibrosis. Journal of Pediatrics, 142(6), 624-630. doi: S0022-3476(03)000593 [pii] 10.1067/mpd.2003.152.

Kuh, D., Power, C., Blane, D., \& Bartley, M. (2004). A life course approach to chronic disease epidemiology. In D. Kuh, C. Power, D. Blane, \& M. Bartley (Eds.), A life course approach to chronic disease epidemiology (2nd ed., pp. 371-398). Oxford: Oxford University Press.

Marmot, M. G., Allen, J., Goldblatt, P., Boyce, T., McNeish, D., Grady, M., \& Geddes, I. (2010). Fair society, healthy lives: Strategic review of health inequalities in England post-2010. London: The Marmot Review.

Mehta, G., Sims, E. J., Culross, F., McCormick, J. D., \& Mehta, A. (2004). Potential benefits of the UK cystic fibrosis database. Journal of the Royal Society of Medicine, 97(Suppl 44), 60-71.

Milton, B., Holland, P., \& Whitehead, M. (2006). The social and economic consequences of childhood-onset Type 1 diabetes mellitus across the lifecourse: A systematic review. Diabetic Medicine, 23(8), 821-829.

Munck, A., Duhamel, J. F., Lamireau, T., Le Luyer, B., Le Tallec, C., Bellon, G., Roussey, M., Foucaud, P., Ginies, J. L., Houzel, A., Marguet, C., Guillot, M., David, V., Kapel, N., Dyard, F., \& Henniges, F. (2009). Pancreatic enzyme replacement therapy for young cystic fibrosis patients. Journal of Cystic Fibrosis, 8(1), 14-18. doi:10.1016/j.jcf.2008.07.003.

Nash, E. F., Kavanagh, D., Williams, S., Bikmalla, S., Gray, A., \& Whitehouse, J. L. (2011). Implications of the current UK welfare reforms for adults with cystic fibrosis. Clinical Medicine, 11(6), 634.

O'Connor, G. T., Quinton, H. B., Kneeland, T., Kahn, R., Lever, T., Maddock, J., Robichaud, P., Detzer, M., \& Swartz, D. R. (2003). Median household income and mortality rate in cystic fibrosis. Pediatrics, 111(4 Pt 1), e333-e339.

ONS. (2011). Indices of deprivation across the UK. http://www.neighbourhood.statistics.gov.uk/ dissemination/Info.do?page=analysisandguidance/analysisarticles/indices-of-deprivation.htm. Accessed 29 July 2011.

Petrou, S., \& Kupek, E. (2005). Socioeconomic differences in childhood hospital inpatient service utilisation and costs: Prospective cohort study. Journal of Epidemiology and Community Health, 59(7), 591-597. doi:10.1136/jech.2004.025395.

Pollock, A. M., Price, D., \& Roderick, P. (2012a). Health and social care bill 2011: A legal basis for charging and providing fewer health services to people in England. British Medical Journal, 344, e1729. doi:10.1136/bmj.e1729. 
Pollock, A. M., Price, D., Roderick, P., Treuherz, T., McCoy, D., McKee, M., \& Reynolds, L. (2012b). How the health and social care bill 2011 would end entitlement to comprehensive health care in England. Lancet, 379(9814), 387-389. doi:10.1016/S0140-6736(12)60119-6.

Ravallion, M. (2001). Growth, inequality and poverty: Looking beyond averages. World Development, 29(11), 1803-1815.

Sawicki, G. S., Sellers, D. E., \& Robinson, W. M. (2009). High treatment burden in adults with cystic fibrosis: Challenges to disease self-management. Journal of Cystic Fibrosis, 8(2), 91-96. doi: S1569-1993(08)00145-8 [pii] 10.1016/j.jcf.2008.09.007.

Saxena, S., Majeed, A., \& Jones, M. (1999). Socioeconomic differences in childhood consultation rates in general practice in England and Wales: Prospective cohort study. British Medical Journal, 318(7184), 642-646.

Saxena, S., Eliahoo, J., \& Majeed, A. (2002). Socioeconomic and ethnic group differences in self reported health status and use of health services by children and young people in England: Cross sectional study. British Medical Journal, 325(7363), 520.

Schechter, M. S. (2004). Non-genetic influences on CF lung disease: The role of sociodemographic characteristics, environmental exposures and healthcare interventions. Pediatric Pulmonology, Supplement 26, 82-85.

Schechter, M. S., Shelton, B. J., Margolis, P. A., \& Fitzsimmons, S. C. (2001). The association of socioeconomic status with outcomes in cystic fibrosis patients in the United States. American Journal of Respiratory and Critical Care Medicine, 163(6), 1331-1337.

Schechter, M. S., McColley, S. A., Silva, S., Haselkorn, T., Konstan, M. W., \& Wagener, J. S. (2009). Association of socioeconomic status with the use of chronic therapies and healthcare utilization in children with cystic fibrosis. Journal of Pediatrics, 155(5), 634-639. e631-634. doi: S0022-3476(09)00455-7 [pii] 10.1016/j.jpeds.2009.04.059.

Schechter, M. S., McColley, S. A., Regelmann, W., Millar, S. J., Pasta, D. J., Wagener, J. S., Konstan, M. W., \& Morgan, W. J. (2011). Socioeconomic status and the likelihood of antibiotic treatment for signs and symptoms of pulmonary exacerbation in children with cystic fibrosis. Journal of Pediatrics, 159(5), 819-824. e811. doi: S0022-3476(11)00483-5 [pii] 10.1016/j.jpeds.2011.05.005.

Smith, J. P., \& Goldman, D. (2010). Can patient self-management explain the health gradient? Goldman and Smith (2002) revisited: A response to Maitra. Social Science and Medicine, 70(6), 813-815. doi:10.1016/j.socscimed.2009.11.010.

Spencer, N., Bambang, S., Logan, S., \& Gill, L. (1999). Socioeconomic status and birth weight: Comparison of an area-based measure with the Registrar General's social class. Journal of Epidemiology and Community Health, 53(8), 495-498.

Stirbu, I., Kunst, A. E., Mielck, A., \& Mackenbach, J. P. (2011). Inequalities in utilisation of general practitioner and specialist services in 9 European countries. BMC Health Services Research, 11, 288. doi: 1472-6963-11-288 [pii] 10.1186/1472-6963-11-288.

Taylor-Robinson, D. C. (2013). The effect of socio-economic status on outcomes in cystic fibrosis. Doctoral thesis, University of Liverpool. http://research-archive.liv.ac.uk/13813/. Accessed 4 Apr 2014.

Taylor-Robinson, D., \& Schechter, M. S. (2011). Health inequalities and cystic fibrosis. British Medical Journal, 343, d4818. doi: 10.1136/bmj.d4818 bmj.d4818 [pii].

Taylor-Robinson, D., Smyth, R. L., Diggle, P., \& Whitehead, M. (2013a). The effect of social deprivation on clinical outcomes and the use of treatments in the UK cystic fibrosis population: A longitudinal study. The Lancet Respiratory Medicine, 1(2), 121-128.

Taylor-Robinson, D. C., Smyth, R., Diggle, P. J., \& Whitehead, M. (2013b). A longitudinal study of the impact of social deprivation and disease severity on employment status in the UK cystic fibrosis population. PloS One, 8(8), e73322. doi:10.1371/journal.pone.0073322.

Thornton, J., Elliott, R. A., Tully, M. P., Dodd, M., \& Webb, A. K. (2005). Clinical and economic choices in the treatment of respiratory infections in cystic fibrosis: Comparing hospital and home care. Journal of Cystic Fibrosis, 4(4), 239-247. doi:10.1016/j.jcf.2005.08.003.

van Aalderen, W. M., Mannes, G. P., Bosma, E. S., Roorda, R. J., \& Heymans, H. S. (1995). Home care in cystic fibrosis patients. European Respiratory Journal, 8(1), 172-175. 
Walker, S. P., Wachs, T. D., Grantham-McGregor, S., Black, M. M., Nelson, C. A., Huffman, S. L., Baker-Henningham, H., Chang, S. M., Hamadani, J. D., Lozoff, B., Gardner, J. M., Powell, C. A., Rahman, A., \& Richter, L. (2011). Inequality in early childhood: Risk and protective factors for early child development. Lancet, 378(9799), 1325-1338. doi:10.1016/S0140-6736(11)60555-2.

Whitehead, M. (1990). The concepts and principles of equity and health. Copenhagen: WHO, Regional Office for Europe.

Whitehead, M., \& Dahlgren, G. (2007). Concepts and principles for tackling social inequities in health: Levelling up Part 1. Copenhagen: WHO.

Whitehead, M., Dahlgren, G., \& Evans, T. (2001). Equity and health sector reforms: Can low-income countries escape the medical poverty trap? Lancet, 358(9284), 833-836. doi:10.1016/S0140-6736(01)05975-X.

Whitehead, M., Hanratty, B., \& Popay, J. (2010). NHS reform: Untried remedies for misdiagnosed problems? Lancet, 376(9750), 1373-1375. doi:10.1016/S0140-6736(10)61231-7. 